\title{
Continuous epidural analgesia, a new prospect in analgesia of newborns
}

\author{
Mixa $\mathrm{V}^{1}$, Nedomova $\mathrm{B}^{2}$, Berka $\mathrm{I}^{3}$ \\ University Hospital Motol, Department of Anaesthesia and Intensive Care Medicine, Prague, \\ Czech Republic.vmxa@volny.cz
}

\begin{abstract}
The popularity of continuous caudal epidural block in post-operative analgesia in very young children has been growing. This method of analgesia is used in major abdominal and urological surgeries. A local anaesthetic, usually levobupivacaine, is administered through an epidural catheter introduced via hiatus canalis sacralis. The usual type of the catheter is Arrow G20 armed with a metal spiral, which can be used for children of up to approximately $2000 \mathrm{~g}$ of body weight. We want to introduce a modification of the method which uses the thin silicone catheter Premicath G28. This catheter allows for the administration of caudal epidural analgesia even in premature children of approximately $500 \mathrm{~g}$ of body weight. This solution eliminates adverse effects of systemic opioid analgesia, accelerates surgical wound healing and disconnection from ventilation system, and improves the potential of enteral nutrition. Depth and quality of analgesia in very young children are monitored using a complex scheme called Comfort Neo Scale (Tab. 1, Fig. 2, Ref. 7). Text in PDF www.elis.sk.

KEY WORDS: paediatric anaesthesia, regional anaesthesia, caudal epidural anaesthesia, Comfort Neo Scale, paediatric perioperative analgesia.
\end{abstract}

\section{Introduction}

Newborns and infants who underwent a surgery because of surgically amendable congenital malformations or serious inflammatory complications need efficient post-operative pain management. The requirements can be met through continuous systemic administration of opioid analgesics, in particular if administered in combination with non-opioid analgesics. However, there are serious side effects, particularly a slowdown in intestinal peristalsis and inhibition of the respiratory centre. These lead to nutritional disorders and prolongation of the post-operative period on mechanical ventilation support with a number of potential further complications. In newborns and infants, opioid analgesics may be replaced with continuous caudal epidural analgesia.

\section{Caudal epidural analgesia}

The basic feature of caudal epidural analgesia lies in administration of a local anaesthetic into the epidural space via hiatus canalis sacralis in the sacrum. This method is used in the management of chronic pain, obstetric analgesia and in particular in anaes-

${ }^{1}$ University Hospital Motol, Department of Anaesthesia and Intensive Care Medicine, Prague, Czech Republic, ${ }^{2}$ Children's University Hospital Bratislava, Department of Pediatric Anaesthesia and Critical Care Medicine, Bratislava, Slovak Republic, and ${ }^{3}$ Institute for the Care of Mother and Child, Charles University in Prague, Prague, Czech Republic

Address for correspondence: $\mathrm{V}$. Mixa, MD, PhD, Department of Anaesthesia and Intensive Care University Hospital Motol, V uvalu 84, CZ-150 06 Praha 5 - Motol, Czech Republic.

Phone: +420.224435481 , Fax: +420.224435420 thesia and analgaesia in paediatrics. A single-use caudal block in combination with general anaesthesia is used for the surgeries of inguinal hernia, testicular retention, in urologic interventions etc. The continuous modification is used with similar success as perioperative analgesia in large proctologic and urologic surgeries (1).

During the past years, the centres which employ the authors of this communication have operated under such combined anaesthesia on an increasing number of children whose weight at the time of surgery was less than $5 \mathrm{~kg}$. The indications for such surgeries comprised mostly congenital anorectal atresia, reconstruction of hypospadia or an advanced stage of necrotising enterocolitis (2) (Tab. 1).

Following the introductory phase of general anaesthesia, establishment of sufficient venous access, and monitoring the blood circulation, a catheter is inserted. With the patient in decubital position, the orientation points of cornua sacralia and tailbone are palpated on the sacrum. As the layer of subcutaneous fat is usually thin, the borderlines can be palpated easily. The material used for

Tab. 1. Indications for the procedure and numbers of patients up to $5000 \mathrm{~g}$ of body weight who received continuous caudal epidural analgesia at the centres employing the authors from January 2013 to August 2014.

\begin{tabular}{lcc}
\hline $\begin{array}{l}\text { Indications of continuous caudal } \\
\text { Epidural analgesia }\end{array}$ & $\begin{array}{c}\text { Number } \\
(\mathrm{n})\end{array}$ & $\begin{array}{c}\text { Average duration } \\
\text { of analgesia } \\
\text { In hours; (range); median }\end{array}$ \\
\hline Anorectal reconstructive surgeries & & \\
Malformations & 9 & $67 ;(22-92) ; 75$ \\
Reconstructive surgeries of hypospadia & 4 & $42 ;(36-48) ; 42$ \\
Atresia of small intestine & 3 & $95 ;(68-116) ; 100$ \\
Necrotising enterocolitis & 2 & $207 ;(135-278) ; 207$ \\
Orthopaedic corrections & 3 & $107 ;(74-160) ; 86$ \\
\hline
\end{tabular}




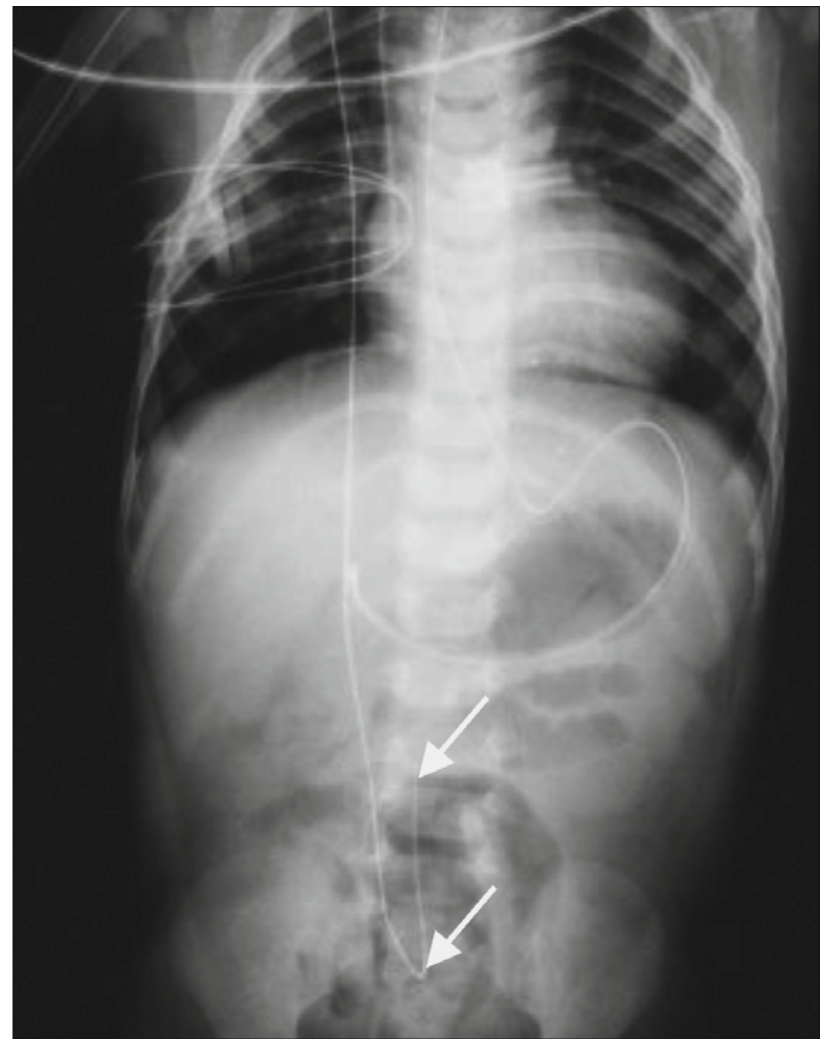

Fig. 1. X-ray of an infant with the Arrow G20 catheter used for continuous caudal epidural block in situ. The arrows point to the puncture site and epidural catheter path.

the block usually differs according to child's age and weight. In children weighing between 2.0 and $5.0 \mathrm{~kg}$, it is usually intravenous cannula G18, through which a G20 catheter armed with a metal spiral (Arrow Int., USA), is inserted to the depth of approximately $3 \mathrm{~cm}$. This catheter is bending-resistant and radio-opaque (Fig. 1). We use a relatively strong cannula for epidural space puncture in order to feel better the resistance put up by respective layers of tissues against the penetrating cannula. The experienced resistance is then used for the sake of orientation. If a too thin cannula is used, the resistance set up by delicate child tissue is weak and difficult to feel, which thus makes the orientation harder (3).

Finer material should be used in children weighing below $2.0 \mathrm{~kg}$. To penetrate the epidural space, a G22 or G24 intravenous cannula is used. After the detection of epidural space, the G28 silicone catheter Premicath (Vigon, UK) is inserted through the cannula. This product was originally meant to serve as a peripherally inserted central venous catheter (Fig. 2).

A single dose of $1.25 \mathrm{mg} / \mathrm{kg}$ of levobupivacaine $0.25 \%$ (Chirocaine Abbott) is administered through this epidural catheter after the insertion, which is followed by a continuous dose of $0.2 \mathrm{mg} / \mathrm{kg} / \mathrm{h}$ of levobupivacaine. For the concentration of $0.25 \%$ and a child weighing $2 \mathrm{~kg}$, the administration rate is $0.2 \mathrm{ml} / \mathrm{h}$. Levobupivacaine was chosen with respect to its comparably lowest cardiotoxicity and neurotoxicity among all currently used local anaesthetics.

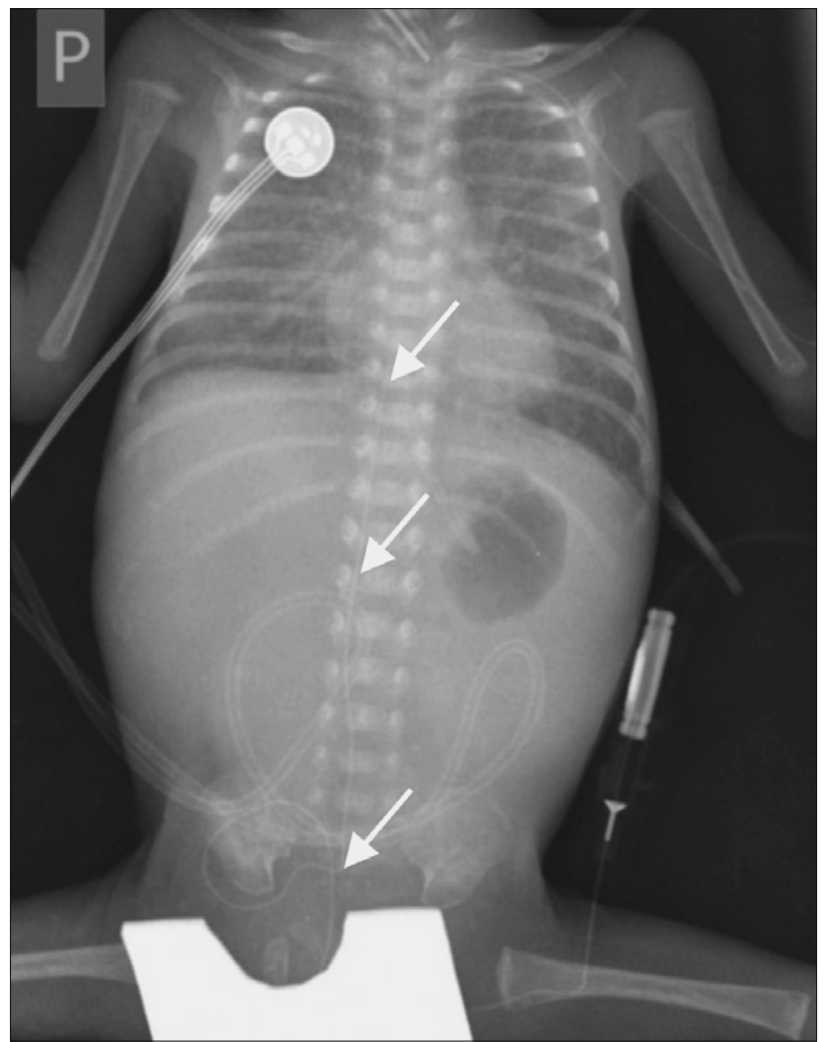

Fig. 2. An X-ray image of a severely immature child ( $530 \mathrm{~g}$ ) with the Premicath G28 catheter used for continuous caudal epidural block. The arrows point to the puncture site and epidural catheter path.

The catheter used for post-operative pain management is usually left in situ for 2-4 days; after that it is removed and epidural analgesia is replaced by systemic administration of non-opioid analgesics. A catheter used for the management of pain caused by an inflammatory or traumatic process may be left in situ for a longer period.

The quality of analgesia achieved is measured using scoring schemes assessing the grade of alteration of various child activities (breathing, consciousness, muscle tone, movement of limbs, etc.). For premature newborns and infants, Comfort Neo Score (4) is used; for children up to one year of age, the scale NIPS (Neonatal/ Infant Pain Scale) can be used. Both schemes can be modified for children who are connected to a mechanical ventilation system.

\section{Case reports}

Two brief case reports attached demonstrate the use of continuous caudal block in analgesia of children with extremely low birth weight. The first case report presents a case of an extremely premature boy (week $23+1,530 \mathrm{~g}$ ), whose adaptation after the birth was complicated by the development of necrotizing enterocolitis (NEC). Enterocolitis gradually required three revision surgeries and the state was very demanding with respect to the provision of subsequent analgesia. The dosage schedule for opioids was insufficient and as systemic analgesia could not provide more 
opportunities, we decided to implement continuous caudal epidural analgesia. We inserted the catheter Premicath G28, which allowed us to normalize the dosage of opioids within a few days and to reach satisfactory values during pain scoring according to Comfort Neo Score (5).

The other patient was a premature twin (week 29+5, $1200 \mathrm{~g}$ ), who had to undergo an amputation of both lower extremities after the birth due to intrauterine necrosis caused by correction of the twin-to-twin transfusion syndrome. This complication required high doses of opioid analgesics and mechanical ventilation from the first day of life and also led to deteriorated tolerance of enteral nutrition. After 15 days of treatment and two revision surgeries, we decided to insert the continuous caudal catheter Premicath G28. It was used for 7 days and helped to overcome the period with highest demands on analgesia. The healing of stubs improved and the requirements for systemic analgesia decreased significantly. Pain scoring and, consequently, the establishment of analgesia dosage were performed using the Comfort Neo Score.

\section{Discussion}

Continuous caudal block has become a successful standard method in peroperative care, both in mature newborns and young infants. The method contributes to post-operative care simplification, reduces the consumption of both opioid and non-opioid analgesics, and reduces their adverse effects (6). The use is limited to diagnoses which usually require a demanding surgery and therefore are managed by few specialized centres. The Arrow G20 catheter used for this procedure is reliable and we have not had any complications for several years.

The use of continuous caudal block using the Premicath catheter is a new method both in anaesthesiology and neonatology and has not been described in literature so far. This procedure is technically convenient and if the principles of asepsis are observed, the catheter can be used for a long time. Continuous epidural block can be used even in children belonging to the lowest weight class. As for pharmacological aspects, continuous long-term administration of levobupivacaine has not been fully investigated. During continuous administration of bupivacaine in very small children, Calder et al (7) discovered that the plasmatic level of the free (i.e. efficient) bupivacaine does not change, but there is gradual accumulation of total, i.e. plasmatic protein-bound bupivacaine. However, the effectiveness and safety of epidural block have not been disputed. In small children to whom we apply continuous epidural block we carefully monitor heart activity and repeatedly perform neurological examinations in order to avoid potential cardiotoxic and neurotoxic complications.

\section{Conclusion}

Continuous caudal epidural block has been accepted as a new progressive method of peroperative analgesia to be used in newborns and small infants. The modification which uses the Premicath catheter represents a new method which can be used for analgesia in severely premature children with borderline viability and effectively expands the options of non-opioid analgesia available for this group of patients. With respect to certain degree of exclusiveness, this method may be used only by experienced staff of clinics of paediatric anaesthesiology and perinatologic centres.

\section{References}

1. Bosenberg A. Benefits of regional anesthesia in children. Pediat Anesthesia 2012; 22 (1): 10-18.

2. Lonnqvist PA. Regional anaesthesia and analgesia in the neonate. Best Pract Res Clin Anaesth 2010; 24: 309-321.

3. Jöhr M, Berger TM. Caudal blocs. Pediat Anesth 2012; 22 (1): 44-50.

4. Van Dijk M, Roofthooft DWE, Anand KJS, Guldemond F, de Graf J, Simons S, de Jager Y, van Goudoever JB, Tibboel D. Taking Up the Challenge of Measuring Prolonged Pain in (Premature) Neonates. The Comfort Neo Scale Seems Promising. Clin J Pain 2009; 25: 607-616.

5. Mixa V, Berka I, Rygl M. Kontinuální kaudální epidurální analgezie extrémně nedonošeného dítěte - kasuistika. Anest Intenziv Med 2014; 25 (3): 190-193.

6. Wolf AR. Effect of regional analgesia on stress responses to pediatric surgery. Pediat Anesth 2012; 22 (1): 19-24.

7. Calder A, Bell TG, Anderson M, Thomson A, Watson DG, Morton NS. Pharmacokinetic profiles of epidural bupivacaine and ropivacaine following single-shot and continuous epidural use in young infants. Pediat Anesth 2012; 22 (5): 430-437. 